\title{
SALUTATION AND HEALTH IN NIGERIAN \\ TRADITIONAL SOCIETY: A STUDY OF SELECTED \\ COMMUNITIES IN THE SOUTH EAST REGION
}

\author{
Bentina Alawari Mathias* \\ \& \\ Blessing Nonye Onyima* \\ http://dx.doi.org/10.4314/og.v11i 1.4
}

\begin{abstract}
Health concerns among Nigerians may have given rise to a covert and an implicit relationship with salutations/greetings. Health has been defined as a state of complete physical, mental and social wellbeing and not merely an absence of disease or infirmity. This is reflected in the traditional normative salutations that one receives or gives when one comes in contact with relatives, neighbors or friends. Instead of the contemporary greetings like good morning, etc., the person is greeted with questions such as: How do you do? How was your night? Is this linked with the health system or fear of the unknown? The reply to any of these questions is often multifaceted and reflects a concern with the physical, mental or social well-being of the individual(s) or groups concerned. This paper examined the $21^{\text {st }}$ century culture of salutations in some selected communities in south eastern Nigeria with the aim of identifying the relationship between salutation and health. Qualitative method of data collection was used to gather information from the communities. Analysis was done using the descriptive method. Results showed a close relationship between salutation and health issues. It also showed that in spite of the fact that modernization has eroded most of our cultural values, the communalist values of the Igbo people are still cherished.
\end{abstract}

Key words: Salutations, health, Igbo, phatic expressions, illocutionary greetings.

\section{Introduction}

Salutation is a sign, act or gesture of greeting exchanges or a way of recognizing somebody. It could also be seen as a verbal conventional expression of friendliness, exchange of shared mutual phrases and 
statements of good wishes and intent within a speech community. This implies that salutations could be signs or verbal expressions. Earlier works had focused on multiple functions of salutations/greetings (Austin, 1962, Goffman, 1967, Firth, 1972). Little has been done on the relationship between health and greetings particularly among the Igbo of Nigeria. Though, Onuigbo, (1993, 1989) had done a thorough ethnography of greetings among the Igbo, yet did not dwell on health-oriented salutations among the Igbo. However, this paper addresses the current knowledge gap and it is focused mainly on verbal salutations and how it relates to health and welfare among the Igbo of south eastern Nigeria. Salutation has been in existence even in the pre-colonial acephalous and stratified clans, villages and communities of the Igbo people. Salutations establish preconditions for social exchanges and interactions. Salutations have overtime attracted scholarly attention for instance, Makoul, Zick \& Green, (2007) highlighted the importance of greeting patients properly and what constitutes appropriate greetings in hospital settings. This according to Makoul et al. (2007, p.1172) is because the "medical literature is devoid of systematic studies on actual greeting behaviours in everyday practice'. There is no point of agreement in terms of conceptualization of greetings among scholars. Though, Duranti (1997, p.63) had earlier argued that there is "no generalizable definition of greetings and what greetings do for people in terms of functional relevance to a community and as such no systematic way of determining what qualifies as greetings". Therefore what constitutes a salutation within a group must be mutually intelligible and shared but may not be shared or intelligible to people outside a particular cultural group. In essence, salutation/greeting patterns remains a culture-bound interactional expression. This implies that there must be an agreed-upon definition of what constitutes a salutation in a speech community. Greetings among the Igbo are speech events, which as interactional encounters are very important indices of proper socialization, the measure of the type of relationship existing between the interactants, as well as the means of maintaining the binding fabrics that holds the 
community together (Onuigbo, 1993). Salutations/greetings are systematically considered under the realm of linguistics, linguistic anthropology, ethnology, and sociolinguistics or within ethnography of communications/speaking and a handful of studies have been done on salutations such as Duranti, (1997). Salutations are ethnographic when they are descriptively centered on culturespecific details and aspects of greeting behaviors (Duranti, 1997). Socio-linguistically oriented salutations are focused on social contexts in terms of conventionally shared ideas and practice on when (time), how, where and what to greet in a particular sociocultural context. Ethnologically driven researches on salutations are geared towards a comparative analysis of greetings cross-culturally in order to ascertain areas of similarities and differences.

In relating salutation with health, our discourse will tend to be illocutionary (concentration on intent of the speaker) in nature rather than on the prevailing concentration on the bio-social functions of salutations in literature. Though Onuigbo, (1993) had earlier noted that greetings/salutations among the Igbo of south eastern Nigeria primarily performs phatic communication functions, while some greetings are used to convey information. The focus here is not that of conveying information but that of extracting new information from the interactants ('greeter and the greeted'). This is pertinent due to, the current deviation from the normative salutation of mere phatic phrases or statements among the Igbo of eastern Nigeria, to extracting deeper information on health and well-being from an individual or group. For instance, Duranti, (1997) had argued against the widespread belief in literature that 'not all greetings are devoid of propositional content (meaning people do not often mean what they say during salutations and as such salutations are mere rituals); in his studies among the Samoans for example, salutations are much more than conventional ritual observation, rather they reveal search for new information and new ideas. He further argued that the prevailing emphasis on the 'social functions' of salutations has led to deviation among scholars from focusing on what people actually say or deeply mean or talk about during 
salutations. Such social function of salutations include; seeing salutations as mere rituals of bonding to eliminate aggressive behaviours against one another, avoidance of physical confrontations, symbol of trust, need for continuity of relationships/friendships, recognition, respect, courtesy, acknowledging another person's presence, among others. Onuigbo, (1993) reveals that greetings among the Igbo as a cultural performance are influenced by social variables such as sex, age and status of the interactants. These variables determine who is culturally expected to greet first during contacts particularly in a patrilineal society like that of the Igbo. The over concentration on these social functions of salutations by linguists and sociolinguist has led to evasion of the prepositional contents of salutations as well as ignoring the verbal content and deeper contextual meanings of salutations. Duranti, (1997) therefore argued that it will take only ethnographically oriented study on salutations to unravel and untangle these deeper webs of meanings during salutations.

Following from the above, this study is set to interrogate question-oriented salutations in relation to health/welfare and to ascertain reasons for the current deviation from the normative phatic phrases commonly known as greetings among communities in Awka south eastern Nigeria.

\section{Method}

This study employed qualitative ethnographic methods such as participant observation (PO) and in-depth interviews (IDI) in eliciting detailed information from randomly selected twenty participants (eight males and twelve females) resident in Awka, Anambra state south eastern Nigeria. Data was collected in Igbo language and in Pidgin English where the need arises. The researchers also employed participant observation as they have both spent a minimum of three to ten years living with the Awka people, participating and interacting with the indigenous people of Awka in their daily activities. The researchers are native speakers of the Igbo language and as such understand the core contents, meanings and 
also possess appropriate communicative competence of the Igbo language and culture.

Awka in Anambra state Nigeria is home of an ancient blacksmithing industrial city. Nigeria has over 250 indigenous ethnic groups out of which three (Hausa, Yoruba and Igbo) are majority. Anambra state is one of the five states occupied by the Igbo ethnic group, and they are generally known as business oriented and achievement driven. The Igbo ethnic group speaks Igbo language but it is pertinent to point of out that there are various variants of the Igbo language involving speakers with diverse accents and dialects. However, the Igbo people understand themselves in spite of the accents and varying dialects because there is what is known as the 'general Igbo language'. Hence, the study area is occupied by indigenes as well as migrant residents from other parts of the country. Thus, the city of Awka is quite a melting pot of cultures. However, some indigenous cultural practices which serve as avenues for expressions and exchanges of salutations, remains prominent such as the famous week long Imo-awka masquerade festival, traditional chieftaincy coronation (ofala), traditional marriages, burial ceremonies (Christian or traditional) among others. Anambra State was created on the $27^{\text {th }}$ of August, 1991 by the then head of state, General Ibrahim Babangida. The state derives its name from the Anambra River and it is made of 21 Local Government Areas. Anambra state is bounded by Delta and Edo States to the West; Imo and Rivers States to the South, Enugu State to the East and Kogi State to the North. The state covers an area of 4,416 sq $\mathrm{km}$ and has typical semi-tropical rainforest vegetation, a humid temperature of about $87^{\circ} \mathrm{F}$ and a rainfall of $152-230 \mathrm{~cm}$ (Egbe, 2004). Anambra State has a population of $4,182,032$, according to the 2006 National Population Census; out of this figure 2,174,641 are males while 2,007,391 are females (National Population Commission, 2006).

The researchers adhered to basic ethical principles of human subject research such as maintenance of confidentiality, informed consent, anonymity of respondents in the course of data collection. Data collected was managed through the use of tape recorder and field 
notes which was later transcribed and translated from the Igbo language to the English language. Analysis was done using the descriptive method. This is to enable some ethnographic extrapolations to be made based on the study objectives.

\section{Findings}

\section{Describing Phatic Salutations among the Igbo}

Through participant observation, the study found that salutations among the Igbo people can be described as time-bound, weather/environmentally determined or season-bound salutations. These time-bound salutations were observed to be brief conventional openings in most social encounters among the Igbo in Awka. As it is the culture of the people to structure their greetings based on the time or period of the day like good morning-ututu oma, good afternoon or happy sunshine-ehihie oma, and good evening-uhuruchi oma. It was observed that there are two forms of time-bound greetings at the close/end of the day, which are good evening and good night. Good evening could come at the onset of the interaction when one recognizes someone in the evenings and decides to chat, but it could also be used while in a hurry or going somewhere else and meets a person on the road whether one knows the person or not. Salutation in this case becomes a cultural necessity among the Igbo, which is expected to be extended to everyone even strangers on the road. This may not be an accepted practice elsewhere in the world to greet strangers you meet on the road. As a matter of fact, greeting a stranger elsewhere maybe frowned at; attract no response or a bizarre stare or even a culture shock. For instance, a respondent who returned home from the United States of America (USA) during the 2014 Christmas celebrations narrated her experience to the researcher as a first-timer in the US:

When I got to the US newly, I discovered that it was snowing and I stepped out to watch and have a feel. As I stepped out, a neighbor also stepped out of his room and I greeted Good morning! His response 
gave me the first culture shock I had in the US. He quickly retorted What is good about the morning?, as if we were quarrelling. I was shocked at his response. I later got to understand the reason behind that response as I continued my stay in the US. It is cultural variation (42 year old male in Amaikwo, Awka, December, 2014).

Contrary to the above, among the Igbo people when one sees a neighbor in the morning and does not greet, it is frowned at and it may also imply disrespect or that there is an unhealthy relationship (a feud, disagreement or conflict) between them. Onuigbo, (1993 citing Okolo, 1990, p.96) had observed that among the Igbo not greeting or even greeting in culturally inappropriate ways can lead to a negative assessment of a person's character. The person may be branded a deviant who is not culture or adequately socialized in the norm and values of the Igbo people. For instance an in-depth interview participant had this to say:

Here salutation is a way of extending good wishes, it fosters good relationship among people and it also implies there is a harmonious relationship between two people or groups; but whenever you notice particular persons not greeting each other, it signifies they are not in good terms. You see this is not so elsewhere or in abroad, neighbours may or may not salute each other, which do not mean they are quarreling (60 year old female in Amaenyi Awka, January, 2015).

The study further found that, good night is different from good evening as it signifies closing salutation, end of interaction for the day or announcement for leave-taking. These time-bound salutations are often the first feature of social interactions among the Igbo in Nigeria but not in all cases. They could also be extension of good 
wishes like ka chi fo meaning let/may the morning come. This implies that the person saluting wishes the saluted life and not death during the night rest or sleep. The responses to the above time-bound salutations are often superficial, a mere ritual that require the predictable same/similar usual quip of "alright" or same to you. The responses are also sometimes reciprocal, repetitive and tautological, for instance, when one greets 'good morning', most often the reply is equally a repeat of 'good morning'. This is why some greeting researchers have concluded that salutations are phatic expressions (Duranti, 1997). This may create a wrong impression that greetings are intuitive and unimportant and may lead to ignoring greetings in research and in everyday encounters (Makoul et al. 2007). According to the Encarta Dictionary (2009), phatic salutations are expressions conveying emotions rather than information; they are spoken in order to share feelings, create goodwill, or set a pleasant social mood, rather than convey any information. For instance, "have a nice day" is phatic phrase which was prevalent during the early $20^{\text {th }}$ century.

The study also found that some phatic salutations could also be described as 'ceremonial salutations', but they are not time-bound salutations as they can be used at any time. For instance, among the Awka Igbo, in certain ceremonies the anchor person or master of ceremony sometimes begins the occasion by saluting the people "Awka deemenu o" meaning "Awka well-done." This could also be used to salute or encourage a worker who is carryout a job or a tedious duty by merely saying "deeme" signifying "well-done" and the response is often 'thanks'. Another similar type of salutation is "nno" meaning welcome, which is used to salute someone who has just returned from a journey.

However, it is pertinent to point out the use of 'welcome' has become a recent occurrence in the greeting patterns among Nigerians in the past two or three decades. The use of "welcome or you are welcome' as a response to most phatic salutations or timebound greetings. For instance, good morning, good afternoon, good evening, good day attracts the response 'welcome or you are 
welcome'. Whatever, informed this sort of response to these salutations is yet to be ascertained. It could be a recent grammatical innovation. Most of the study participants opined the use of 'welcome' as response to salutations is due to modernization, influences from watching home videos and foreign movies. People copy every life-style they watch on the televisions, internet and interactions from the recent wave of social networks.

\section{Interrogating Question-Oriented (Probe) Salutations in Relation to Health/Welfare among the Igbo}

On the other hand, the study found that there are other more prevailing forms of greetings that are health/welfare-oriented, such salutations are neither phatic nor time-bound, and they could be expressed at any time of the day during interpersonal interactions. These recent types of salutations are not just structured in phrases or statements alone but are also structured in form of questions and they are otherwise known in this paper as probe salutations. A study participant said, "Anyi na-aju ajuju n'ekele ndi ahu ka anyi mara ma udo odikwa, ma obu ka a mara na onye ahu o choro enyemaka, $O$ na-egosi na mmadu na ibe ya no n'udo" (60 year old woman in Okpuno Awka). This participant thinks that probe salutations reflect the people's desire to know if there is peace and that all is well with the person and to ascertain if the person needs help. It also shows that there is cordial relationship between those exchanging greetings. It is evident that these greetings are welfare and health oriented probes designed to subtly pry into and also to elicit new and deeper information from/about others. According to Onuigbo (1989) greetings among the Igbo are elaborate and asking after health relations of the other party is not only evidence of the cordiality of the relationship but also a part of ones competence in greetings. Probe salutations are often not brief they initiate longer and detailed responses on the health and welfare of the person or people concerned. It was observed that among the Igbo of south eastern Nigeria though this practice is not peculiar to the Igbo. The initiator of the salutation often begins with a phatic salutation like "good 
morning" as an opening salutation, and then proceeds with the question oriented salutations. Such salutations are: How are you and your family doing? How do you do? How was your night? How is your body? Or, How is/was your day? The reply to any of these questions is often multifaceted and to a large extent reflects an inquiry into the physical, mental or social well-being of the individual(s) or groups concerned. Following the WHO 1978, and 2004 definition of health, such salutations could be described as 'health/welfare-oriented salutations'. Responses to such salutations are often detailed and they may be positive or negative. For instance, a 56 year old female respondent in Amaenyi Awka has this to say:

Elsewhere in the world like in the UK, If someone asks you how you are? Always pretend to be fine. It's not acceptable to say otherwise because people don't want to be burdened by your worries. If you tell them you're not fine, they probably won't ask again. But here in Igboland, when a person initiates a greeting by saying good morning or good afternoon depending on the period of the day, the response is always 'Good morning'! This is later followed by Unu putakwara? Meaning hope you all survived the night? The expected response is always positive by saying Anyi putara 'yes we all survived' but depending on the type of relationship existing between the two, the person may choose to be open or more detailed about his/her family welfare or health status if they are close friends or blood relatives and in this case the response is often Anyi putara, mana... meaning we all survived the night but... then, he/she may start telling what the exact situation/status of family looks like.

Positive response may not require further probing but a negative response often requires that the person saluting through probes 
may/should out of sincere concern probe more to find out what the problem is/was. This practice is not peculiar to the Igbo but has also been observed among the Yoruba of south western Nigeria. The Yoruba are known for their long-unending greetings, they will probe to ascertain the innermost core of friend's life and family. For instance, they will ask 'Anwo omo nko? Oko enyi nko? Baba nko?, Oja nko?' Meaning- How about your children? How is your husband? How is your father? How is your business doing? Sometimes, positive response to question-oriented salutations is the usual predictable "fine". The response 'fine' does not often convey the true picture of the social, mental, economic and physical condition of the person responding. This is because people do not often want to discuss their problems with anyone, since it is difficult to ascertain the true intension of the person saluting. Thus, responses to such question-oriented salutations may be evasive in nature and the person responding may display some uneasiness in order to restrict further probes. The intent of the initiator may be negative, targeted at mockery, gossip, envy or to know the true status of things going on in someone's business, family or finances etc. Although, people are expected to provide a positive assessment of one's self by saying fine, good, ok, regardless of how they are actually feeling or doing at the moment (Duranti, 1997, p.85). However, within the Igbo context, cordiality of previous relationships is the only basis for such welfare-health oriented salutations. If cordiality does not exist previously, then the initiator may or may not salute at all and since it is a cultural necessity to greet enemies and friends, the initiator may resort to stick to only phatic salutations alone and not probe salutations. For instance, an in-depth interview participant at Ifite Awka stressed:

Look, if I am not in a harmonious relationship with someone due to a quarrel or disagreement, I will not greet that person but you know people will always frown at such behavior, so I will just say good morning and go my way. There is no need to query 
or probe or ask how you are or how is your family? Since, we are not in a harmonious relationship, (36 year old female at Ifite, January 2015).

There is therefore need to ascertain reasons for the prevalence of health/welfare-oriented salutations among the Igbo and by extension Nigerians in the $21^{\text {st }}$ century.

\section{Ascertaining Reasons for the Current Practice/Deviation from the Normative Phatic Phrases to health/welfare (probe) - oriented salutations.}

The study found through in-depth interviews that reasons for healthoriented salutations stem from common deep-rooted concerns/fear of uncertainties surrounding survival in Nigeria and also it reflects mere good wishes/intensions depending on the context. For instance, an in-depth interview participant has this to say when probed on the reasons for health-oriented salutations among the Igbo:

My dear, one Igbo musician sang: Onye i huru taa, $i$ gaghi ahu ya echi, Chineke ти o, o bu otu uwa di. Meaning that you may find someone today and the next day they will tell you that the person you ate and dined with last night just died, so one is expected to inquire about the health and welfare of others during salutations (45 year old man in Amaikwo Awka, IDI 2015).

Life expectancy in Nigeria is short and in the Nigerian parlance 'brief', the Nigerian situation has been properly captured by Nnonyelu (2014):

Average life expectancy in Nigeria is about 47 years, while more than 130 million Nigerian live below the poverty line. Brief illness and several other diseases continue to send Nigerians to their 
untimely deaths. The situation in the country over the years has become so tragic that the country is variously described as the "grave yard" "refugee camp" or den of corruption". The net effect of all these is reflected in the palpable loss of selfconfidence, dignity and efficacy (Nnonyelu, in the New Telegraphy Newspaper of 2014, p.5).

Thus, it is often seen as a privilege waking up the next day to find that everyone is alive in Nigeria. Thus, the Igbo people take out time to inquire about the welfare and health status of members of one's relative', neighbors' and friends' family. An in-depth-interview (IDI) participant has this to say when queried on the reasons for prevalence of welfare-health oriented salutations among the Igbo:

The Igbo people's cultural belief is $n d u$ bu isi (meaning life is the ultimate), without life nothing else works and you know any formality in salutations without concerns for one's welfare is useless (30 year old Lecturer, Personal interview, January 2015).

Another interview participant linked health-oriented salutations to the problems of under-development and poverty in Nigeria:

You see, if one listens to the rate of accidents and carnages on Nigerian high ways due to bad roads and pothole-filled roads, unfortunate deaths due to torture from kidnappers, rapists and armed robbers. Also in Nigeria one is not sure of where and when the next meal will come from, there is high rate of diseases and Nigeria health system and health services is not optimally functional. So you see reasons why health-oriented salutations prevail in 
Nigeria (40 year old male Lecturer at Ifite Awka, January 2015).

That is why the Igbo take out time to greet and ask about welfare and health of relatives and friends during salutations. Probe salutations therefore have a lot to do with the nature of family relations, kinship relations, communalism and mutual interdependence, poverty and under-developed health systems existing among the Igbo people of south eastern Nigeria.

\section{Discussion}

We have arguably highlighted in this paper that there is a significant relationship between salutations and health/welfare issues. For instance, in a study carried out by physicians in the United states, Makoul et al. (2007,p.1174) had stressed that "while greetings may rather seem a mundane aspect of physician-patient communication, attention to this task can set a positive for the encounter and increase chances of developing a therapeutic clinical relationship'. This study agrees with Machino (2014) that these question-oriented salutations are illocutionary (intent driven). They intent of these health-oriented are often positive when there is a previously existing harmonious relationship but may sometimes be negative when there is tension or conflicts between the interactants. We have also highlighted that there are various types of salutations namely phatic time-bound salutations (which are often opening or initiation salutations) and health/welfare oriented salutations. First these phatic time-bound salutations arguably are mere translations from the English version of the same time-bound salutations; a reflection of the extent of western cultural influence on the lives and culture of the Igbo in the $21^{\text {st }}$ century. The health oriented salutations are a deviation from the normative western-influenced phatic phrases/expressions which prevailed during early $20^{\text {th }}$ century. The health/welfare-oriented salutations paint a better picture of the communalistic culture of the African man and in specifics the Igbo people. The Igbo social life is/was anchored on brotherhood, love, sharing without reckoning 
and egalitarianism prior to the contact with westernization. We have also been able to distinguish between interaction-initiation salutations and closing or leave-taking salutations. A study conducted by Michino, $(2014$, p. 2) asserts that "there is a significant difference along cultural and linguistic lines in terms of subject's perception of and conformance to distinct greetings and leave-taking norms which persist across multiple generations and are consistent among language dominance groups".

In a greeting survey of patient's preferences on 'beginning interaction with a psychiatrist', Vinjamuri, Nehal, and Latt, (2009) asserts that greetings constitute an important way of establishing the therapeutic relationship with patient and as such should be given appropriate attention. Motivations for whatever kind of salutation (verbal or non-verbal) has not been properly researched as pointed out by Thanissaro (2010) who recommended further research in this area. Though, his study found that a form of non-verbal salutation (bowing to parents) is significantly related to spiritual attitudes among adolescents. In this study, motivations for welfare-health oriented salutations may be also informed by cultural socialization and social expectations rather than religious (though religious motivation may not be ruled out) among the Igbo of south eastern Nigeria. Salutations may be rooted in adherence to morals, though; Nigeria is a morally conscious society and can best be described as notoriously religious.

Again, these health-oriented salutations in this paper have been linked with the unconscious concerns about the poor status of the Nigerian health systems, dilapidated and ill-equipped health facilities and poor health services in general. For instance, Omar 2008 has argued that the National health policy (NHP) in Nigeria was launched in 1988 with the main objective of 'health for all by the year 2000' remains a dream and seems to be as remote as ever among the Nigerian people. He further argued that 'the provision of an effective system of health care delivery as a right, and not as a privilege, is but a dream in Nigeria. 'The failure of the Nigerian state to provide an effective, functional and sustainable health care system 
where access to health care system is not possible for majority of the populace' (Omar, 2008, p.22). A populace faced with this type of failed health care system may not be estranged from practicing health/welfare-oriented salutations. It may serve as shared coping strategy, citizen's succor or palliative measure in a shared experience of a failed health system.

\section{Conclusion and Recommendations}

In sum, we have been able to x-ray the reasons for question-oriented salutations. We stressed that these question-oriented salutations seem to be focused on health/welfare-oriented probes. This is in a bid to elicit new and deeper information among the cultural performers. Study revealed that health-oriented salutations are expressions of deep-rooted unconscious concerns of a failed health system and also low life expectancy in Nigeria. We therefore recommend that there is a necessity for a longitudinal ethnographic survey or further studies on cross-cultural salutations (inter-cultural salutations) in Nigeria. This will provide ethnological insights on similarities and differences of salutation patterns among the various ethnic groups in Nigeria and help in unraveling detailed motivations for welfare-health oriented salutations among Nigerians. For instance, the Yoruba of western Nigeria are known to display a high array of such question oriented salutations. An ethnological study in this area of question-oriented greetings across societies will go a long way in deepening our illocutionary understanding of salutations in Nigeria.

*Bentina Alawari Mathias, Department of Society and Anthropology, Nnamdi Azikiwe University, Awka Bentinad1@yahoo.com,

*Blessing Nonye Onyima, Department of Sociology and Anthropology, Nnamdi Azikiwe University, Awka Nonyelin2003@yahoo.com, 


\section{References}

Austin,J.L.(1972). How to do things with words. Mass: Havard University Press.

Duranti, A. (1997). Universal and culture-specific properties of greetings. Journal of linguistic Anthropology 7(1)63-67.

Egbe, G.A. (2004). Anambra State Latest News and Current Affairs Awka: Anambra State Government in Conjunction with PAGAB Educational Publishing Company.

Firth, J.R. (1972). Verbal and Bodily Ritual of Greeting and Parting. In J.S. La Fountaine (Ed.) Interpretation of Ritual. London Tavistock

Goffman, E. (1962). Interaction ritual: essay on face to face bahaviour. Garden city New York Doubleday.

Machino, J.A. (2014), Greetings and leave-taking in Texas: perception of politeness norms by Mexican-Americans across sociolinguistic divides. A report presented to the faculty of graduate school of the University of Texas at Austin in partial fulfillment for a degree of Masters of Arts.

Makoul, G., Zick, A. \& Green, M. (2007). An evidence based perspectives on greeting in medical encounters. Arch.Intern.Med.167:1172-1176.

Omar, M. (2008). Governance and primary health care delivery in Nigeria. In Sama M. \& Nguyen, V.(eds.) Governing health systems in Africa. Senegal CODESRIA.

Onuigbo, G.N. (1993). Ethnographic Analysis of Igbo Greetings. African Languages \& Cultures, 6(1):37-48.

Onuigbo, G.N. (1989). Linguistic Politeness in Igbo. Multilingual journal of cross-cultural and inter-language communication 8(2-3): 259-276. 
Vinjamuri, I.S., Nehal, M.A \& Latt, M.M. (2009). Greeting survey. Psychiatric bulletin, 33:313-316.

Thanissaro, P.N, (2010). 'Heaven starts at your parent's feet': Adolescents bowing to parents and associates spiritual attitudes. International journal of children spirituality 15(4)295-304.

WHO, 2004. World Health Organization Regional Office for Africa Country Health Systems Profiles: Nigeria Division of Health Systems and Services Development. Brazzaville, WHO Regional Office for Africa.

WHO, 1978. Alma-Ata: Primary Health Care. Report of the International Conference on Primary Health Care. USSR 6-12 ${ }^{\text {th }}$, September. 